\title{
Youth and the Crisis: Unemployment, Education and Health in Europe
}

\section{Gianluigi Coppola and Niall O'Higgins, eds.}

Abingdon: Routledge, 2016, pp. XIII + 293

ISBN 978-1138897779

doi:10.15179/ces.18.1.6

The chapters were originally papers delivered at a conference in Salerno in 2013. All the authors are economists who apply econometrics to appropriate data sets. Nearly all the authors are based at or are affiliated to Italian academic institutions, and most of the chapters are specifically about Italy. The editors introduce, but do not attempt to synthesize the book's contents which would be difficult and probably impossible. Most chapters are about education, training or health on the one side, and labor market conditions and experiences on the other.

The editors have organized the book in three sections. The first deals with education and training. This section includes the sole chapter with no Italian connection. Paul Ryan (UK) uses data from the UK, Germany and Switzerland to discuss whether the concept of monopsony (a state between monopoly and perfect competition) helps to explain employers' and labor's behavior in training and skilled job markets. In the other chapters in this section, Floro Ernesto Caroleo and Francesco Pastore deal with over-education; Roberto Zotti, then Lara Gitto, Leo Fulvio Minervini and Luisa Monaco tackle drop-out from universities, and Enrico Conti, Silvia Duranti, Carla Rampichini and Nicola 
Sciclone consider pupil achievements in primary schools. All these chapters are wholly or partly based on data from Italy.

The second section is an assortment of contributions on health, leaving home (by young people), and inter-generational mobility. Three chapters tackle health. Gianluigi Coppola, Niall O'Higgins and Claudio Pinto use data from sweeps at ages 26 and 29 of the 1970 British birth cohort to seek effects of income changes on smoking and alcohol consumption, and thereby on body mass index scores and self-rated heath. In the second chapter on health, Giovanni S. F. Bruno, Floro Ernesto Caroleo and Orietta Dessy use data collected in 2006, 2008 and 2010 from 15-35-year-olds in an Italian panel study to explore connections between being overweight or obese on the one hand, and wages and job satisfaction on the other. In the third, health chapter, Orietta Dessy examines relationships across Europe between experiences of unemployment before age 30, and health outcomes after age 50. Unsurprisingly, all these chapters conclude that it is difficult to infer causality in the relationships discovered in the data, and in Dessy's chapter it proves equally difficult to explain why the relationships are so different in different European countries. In the two "leaving home" chapters, Francesca Modena and Concetta Rondinelli show that rising house prices in Italy have delayed this life event, while Fernanda Mozzotta and Lavina Parisi find that in all southern European countries home-leaving raises risks of poverty, especially for young adults from low-income families, and that these effects have become stronger since 2008. In the final chapter of section two, Federica Roccisano shows that young Italians' prospects of upward inter-generational mobility have declined since the mid-20th century.

The third section is headed "Youth Labor Markets, NEET and the Crisis" but only one of the three chapters deals with "the crisis". Guido Cavalca shows that since 2007 youth unemployment and NEET rates in southern European countries have been slower to decline alongside rises in GDP than in other parts of Europe. In the other two chapters, Chiara Mussida and Dario Sciulli show that between 1985 and 2003 the chances of 15-34-year-old Italian non-employed 
males exiting this state were better than females' chances, but with differences by types of occupations and regions, and Guido Cavalca argues convincingly that NEET is a confusing concept, which was the conclusion of UK researchers in the late 1990s when the concept was being adopted by the European Commission from where it has spread into Italy.

This book's title is rather misleading because few of the chapters address a crisis. There is no attempt anywhere to define "crisis". I would define it as an intolerable situation to which there is no known solution. There was a brief financial crisis in 2007-08 and a subsequent more prolonged euro zone crisis. Since then, youth unemployment rates have remained "a problem" throughout most of Europe, but this "problem" has persisted since the 1970s in some countries and is clearly not a systemic crisis. High levels of youth unemployment can be absorbed as episodes in early working lives otherwise spent in short-lived jobs or training. Levels of unemployment can be contained by expanding technically superfluous education and training, by creating low-paid, part-time, temporary and other forms of precarious employment, and wage subsidies. There are few, if any, households where no one in a family has worked for two or more generations, but persistent labor market conditions have created a "class" of households containing adults of working age for whom "welfare" is a normal component in their budgets, and who have accumulated considerable know-how on how to best use welfare entitlements. This may be a persistent situation, and it may be regarded as a problem, but we have surely learned that it is not a crisis.

I cannot imagine any rational economic actors paying $£ 95$ for this book unless the actor is a librarian who will probably take the e-edition. It is not a student text, or for cover-to-cover reading by anyone (except reviewers). Labor economists will pick and dip according to their special interests, if their library has an e-copy. 